\section{Vol. 67, No. 45}

In Table 2 of the report "Suicide Rates by Major Occupational Group - 17 States, 2012 and 2015," on page 1255, some percentages were calculated using records with Standard Occupational Classification (SOC) codes as the denominator rather than all suicide decedents aged 16-64 years. The corrected Table 2 follows. The ranking of occupational groups by suicide rate is unaffected by this correction. On page 1254, the first sentence of the second complete paragraph should have read, "In both 2012 and 2015, the largest percentage of male suicides (15\%-16\% of decedents) occurred among those in the Construction and Extraction group (SOC 47) (Table 2); the largest percentage of female suicides in both years occurred among decedents with unpaid occupations (29\%). The largest percentage of female suicides among classifiable occupations occurred in the Office and Administrative Support group (SOC 43) in both years (9\% and $\mathbf{1 0 \% ) . " ~}$
TABLE 2. Number and percentage of suicide decedents* in Standard Occupational Classification (SOC) major group, by year and sex National Violent Death Reporting System, 17 states, ${ }^{\dagger} 2012$ and 2015

\begin{tabular}{|c|c|c|c|c|c|}
\hline \multirow[b]{2}{*}{$\begin{array}{l}\text { SOC } \\
\text { code }\end{array}$} & \multirow[b]{2}{*}{ Occupational group } & \multicolumn{2}{|c|}{ Male } & \multicolumn{2}{|c|}{ Female } \\
\hline & & $\begin{array}{c}2012 \\
\text { no. }(\%)\end{array}$ & $\begin{array}{l}2015 \\
\text { no. }(\%)\end{array}$ & $\begin{array}{c}2012 \\
\text { no. }(\%)\end{array}$ & $\begin{array}{c}2015 \\
\text { no. }(\%)\end{array}$ \\
\hline 11 & Management & $534(7)$ & $611(7)$ & $117(5)$ & $118(4)$ \\
\hline 13 & $\begin{array}{l}\text { Business and Financial } \\
\text { Operations }\end{array}$ & $155(2)$ & $145(2)$ & $81(3)$ & $84(3)$ \\
\hline 15 & Computer and Mathematical & $208(3)$ & $237(3)$ & $22(1)$ & $32(1)$ \\
\hline 17 & Architecture and Engineering & $172(2)$ & $167(2)$ & $10(<1)$ & $15(1)$ \\
\hline 19 & $\begin{array}{l}\text { Life, Physical, and Social } \\
\text { Science }\end{array}$ & $56(1)$ & $52(1)$ & $15(1)$ & $21(1)$ \\
\hline 21 & Community and Social Service & $41(1)$ & $48(1)$ & $39(2)$ & $40(1)$ \\
\hline 23 & Legal & $54(1)$ & $49(1)$ & $34(1)$ & $29(1)$ \\
\hline 25 & $\begin{array}{l}\text { Education, Training, and } \\
\text { Library }\end{array}$ & $91(1)$ & $87(1)$ & $82(3)$ & $84(3)$ \\
\hline 27 & $\begin{array}{l}\text { Arts, Design, Entertainment, } \\
\text { Sports, and Media }\end{array}$ & $140(2)$ & $186(2)$ & $54(2)$ & $76(3)$ \\
\hline 29 & $\begin{array}{l}\text { Health Care Practitioners and } \\
\text { Technical occupations }\end{array}$ & $145(2)$ & $169(2)$ & $220(9)$ & $225(8)$ \\
\hline 31 & Health Care Support & $35(<1)$ & $34(<1)$ & $97(4)$ & $124(5)$ \\
\hline 33 & Protective Service & $232(3)$ & $226(3)$ & $29(1)$ & $32(1)$ \\
\hline 35 & $\begin{array}{l}\text { Food Preparation and Serving } \\
\text { Related }\end{array}$ & $214(3)$ & $301(3)$ & $112(4)$ & $154(6)$ \\
\hline 37 & $\begin{array}{l}\text { Building and Grounds } \\
\text { Cleaning and Maintenance }\end{array}$ & $316(4)$ & $315(4)$ & $36(1)$ & $46(2)$ \\
\hline 39 & Personal Care and Service & $81(1)$ & $85(1)$ & $98(4)$ & $102(4)$ \\
\hline 41 & Sales and Related & $555(7)$ & $553(6)$ & $170(7)$ & $212(8)$ \\
\hline 43 & $\begin{array}{l}\text { Office and Administrative } \\
\text { Support }\end{array}$ & $244(3)$ & $260(3)$ & $234(9)$ & $268(10)$ \\
\hline 45 & Farming, Fishing, and Forestry & $68(1)$ & $71(1)$ & $7(<1)$ & $5(<1)$ \\
\hline 47 & Construction and Extraction & $1,216(15)$ & $1,404(16)$ & $12(<1)$ & $17(1)$ \\
\hline 49 & $\begin{array}{l}\text { Installation, Maintenance, and } \\
\text { Repair }\end{array}$ & $549(7)$ & $621(7)$ & $8(<1)$ & $N R(<1)$ \\
\hline 51 & Production & $605(7)$ & $679(8)$ & $64(3)$ & $81(3)$ \\
\hline 53 & $\begin{array}{l}\text { Transportation and Material } \\
\text { Moving }\end{array}$ & $736(9)$ & $817(9)$ & $52(2)$ & $39(1)$ \\
\hline NA & Military & $228(3)$ & $203(2)$ & $15(1)$ & $13(<1)$ \\
\hline NA & Unpaid & $822(10)$ & $913(11)$ & 724 (29) & $795(29)$ \\
\hline NA & $\begin{array}{l}\text { Insufficient Information to } \\
\text { Classify Occupation }\end{array}$ & $651(8)$ & $425(5)$ & $177(7)$ & $123(4)$ \\
\hline
\end{tabular}

Abbreviations: $\mathrm{NA}=$ not assigned; $\mathrm{NR}=$ not reported because cell size $<5$.

* Aged 16-64 years; column percentages do not sum to $100 \%$ because of rounding.

† Alaska, Colorado, Georgia, Kentucky, Maryland, Massachusetts, New Jersey, New Mexico, North Carolina, Ohio, Oklahoma, Oregon, Rhode Island, South Carolina, Utah, Virginia, and Wisconsin. 